\title{
Impacts of Demographic Trends on US Household Size and Structure
}

Leiwen Jiang

Watson Institute for International Studies, Brown University, Providence, USA, and International Institute for Applied Systems Analysis, Laxenburg, Austria

Brian C. O'Neill

International Institute for Applied Systems Analysis, Laxenburg, Austria

RP-07-004

October 2007

Reprinted from Population and Development Review 33(3): 567-591 (September 2007) 
IIASA Reprints make research conducted at the International Institute for Applied Systems Analysis more accessible to a wider audience. They reprint independently reviewed articles that have been previously published in journals. Views or opinions expressed herein do not necessarily represent those of the Institute, its National Member Organizations, or other organizations supporting the work.

Reprinted with permission from Population and Development Review 33(3): 567-591 (September 2007)

Copyright (C) 2007

All rights reserved. No part of this publication may be reproduced or transmitted in any form or by any means, electronic or mechanical, including photocopy, recording, or any information storage or retrieval system, without permission in writing from the copyright holder. 


\title{
Impacts of Demographic Trends on US Household Size and Structure
}

\author{
LEIWEN JIANG \\ BRIAN C. O'NEILL
}

HOUSEHOLD SIZE and composition have changed greatly since the founding of the United States, a result of a continuous process of household fission and decline in the importance of the family (Kobrin 1976; Ermisch and Overton 1985). Progression through the traditional family life cycle has become less common as people remain unmarried for longer, cohabitation and union dissolution have become easier and more acceptable, and the remarriage rate has declined. These social adjustments are reflected in large changes in demographic measures of household characteristics. The average household size has more than halved since 1790, dropping from 5.8 persons per household to 2.62 in 2000 (US Census Bureau 2005). The proportion of single-person households increased from 3.7 percent in 1790 to 13 percent in 1960 and to 26 percent in 2000. And nonfamily households consisting of people who live alone or share housing with nonrelatives are on the rise.

While the change in household composition has been continuous, it accelerated after 1960. In 1960, 85 percent of households were family households; this figure dropped to 69 percent by 2000 . Two-parent family households with children declined from 44 percent to 24 percent of all households between 1960 and 2000. Over the same period, unmarried-couple households increased from less than 1 percent to about 5 percent of total households and became progressively more likely to include children. The number of singleparent (primarily single-mother) households increased from 1.5 million in 1950 to 9.5 million in 2000 (Bianchi and Casper 2000).

Most of these changes in household formation and dissolution occurred during the first half of the period since 1960, before the early 1980s. Trends since the 1980s suggest a slowing or even in some cases a cessation of changes in household living arrangements: very little change in the proportion of two-parent or single-mother households, stabilized living arrangements for young adults and the elderly, a slowing growth in cohabitation, a decline in 
divorce, and an almost unchanged average household size during the 1990s. It is unclear whether this recent stability indicates a new sustained equilibrium or is just a temporary lull (Bianchi and Casper 2000).

In this article we develop a set of projections of future living arrangements to explore this question. Anticipating changes in the number, size, and composition of households is important for many issues of social concern. For example, the living arrangements of the elderly are a key determinant of their needs for socioeconomic, physical, and emotional assistance. Older persons who live alone are more likely to be poor than older persons who live with their spouses (Dalaker 1999), and they have greater needs for healthcare. Projections of household growth and its composition by size are also crucial inputs to the development of housing policy for many state and local governments (Holmberg 1987; King 1999; Muller et al. 1999). In addition, much research stresses the importance of household characteristics, especially those linked to household life cycle stages, for understanding savings and consumption patterns. These patterns not only have implications for welfare at the household level, but may also have substantial macro-economic effects (Deaton and Paxson 2000; Tsai et al. 2000; Gokhale et al. 1996). Household type and size also strongly affect the mix of consumption across different types of goods (Wilkes 1995).

Furthermore, shifts in the distribution of households by type and size, through their effects on consumption patterns, have environmental consequences ( $\mathrm{O}^{\prime} \mathrm{Neill}$ et al. 2001). Recent work links changing living arrangements to effects on biodiversity (Liu et al. 2003), land use (Perz 200 1; MacCracken et al. 1999; Van Diepen 1995), carbon dioxide emissions (Dalton et al. 2006), household energy use (O'Neill and Chen 2002; Jiang 1999; MacKellar et al. 1995), transportation (Prskawetz et al. 2004; Carlsson-Kanyama and Linden 1999; Select Committee on Environment 1998), and water use (Jiang 1999; Martin 1999). This emerging line of work moves beyond the traditional approach of treating population size as the only relevant demographic variable when considering environmental impacts.

A number of studies, particularly in the 1970s and 1980s, investigated the demographic determinants of past household changes in the United States (Burch 1970; Burch and Matthews 1987; Carliner 1975; Ermisch and Overton 1985; Kobrin 1973, 1976; Richards, White, and Tsui 1987; Santi 1987, 1988; Sweet 1984; Teachman 1982; Watkins, Menken, and Bongaarts 1987; White and Tsui 1986). While each is informative, most focus only on the determinants of a certain household type (e.g. family households, single-mother households, or elderly households), or on the influence of one demographic phenomenon (e.g., mortality or fertility). Conclusions have not always been clear since demographic factors can have multiple effects on household types. For example, the effect of immigration is complicated by a variety of patterns of residence upon arrival in the United States (Hunton 1998) and by changes after arrival as economic and social situations change (Burr and 
Mutchler 1993). The effects of fertility and mortality on household size have been shown to vary over time as underlying demographic conditions change (Kobrin 1976). In some cases studies have even been contradictory. For example, Burch (1970) concluded that under all family systems (nuclear, stem, and extended), life expectancy is positively correlated with average household size. On the other hand, Kobrin (1976) maintained that mortality decline increases the proportions of one- and two-person households and therefore contributes to a fall in household size.

Although a number of household simulation models have been developed over the past three decades, we are not aware of any systematic study of the influence of demographic factors on household changes. Several studies have reviewed changes in household headship and its determinants in the United States, but they either related those changes to general socioeconomic (rather than demographic) conditions (Carliner 1975) or decomposed the separate influences of changing population structure and propensities of household formation (Carliner 1975; Kobrin 1973). Such studies cannot identify how specific demographic factors lead to particular changes in household composition. A recent effort by Zeng et al. (2006), using the extended household projection model ProFamy, developed three scenarios of future household change for the United States. Assumptions about future fertility, mortality, and migration were adopted from the US Census Bureau's 2000 population projection, and, in the absence of available scenarios for rates of union formation/dissolution, arbitrary assumptions were used.

In this study we use ProFamy to construct a set of scenarios for the United States intended to span a wide but plausible range of outcomes for population composition by household age structure and size and to investigate the sensitivity of outcomes to assumptions about trends in various demographic events. This task requires scenarios for familiar components of change in a population projection (fertility, mortality, and migration) and for factors affecting household formation and dissolution such as divorce, cohabitation, age at leaving home and age at marriage, and propensity of the elderly to live with children. Here the literature is sparse and we break new ground in justifying our scenarios on the basis of past trends and theoretical reasoning.

\section{Data and methodology}

We adopt the macro-dynamic household projection model ProFamy developed by Zeng and his collaborators (Zeng, Vaupel, and Wang 1997, 1998). Zeng extended Bongaarts's nuclear status life table model (Bongaarts 1987) into a general family household simulation macro model that includes both nuclear and three-generation family households (Zeng 1986, 1988, 1991). That model was further extended and developed into a two-sex dynamic model, known as ProFamy, that permits demographic schedules to change over time 
and requires only conventional data sources such as survey data, vital statistics, and census data (Zeng, Vaupel, and Wang 1997, 1998). Projections are performed based on status transition rates, and distributions of households by size and type are then derived based on characteristics of reference persons (or household "markers") in a manner that produces consistent projections of households and individuals. Individuals in the projected population are classified according to eight dimensions of demographic status: age, sex, marital status, parity, number of children living at home, co-residence with parents, private or collective household, and race. ProFamy has been used to make population and household projections for China (Zeng, Wang, Jiang, and Gu, forthcoming) and two regions of China (Jiang 1999), Austria (Prskawetz, Jiang, and O'Neill 2004), Germany (Hullen 2003), and the United States (Zeng et al. 2006).

Projections require data on base-year population and household type and estimates of current summary measures and standard schedules, which we adopt from Zeng et al. (2006). We develop our own scenarios of future summary measures of fertility, mortality, union formation and dissolution, migration, leaving the parental home, and mean ages of leaving the parental home, marriage, and giving birth. The model distinguishes four races (white non-Hispanic, black non-Hispanic, Hispanic, and others), although in this study we assume that summary measures change by the same proportion across all race categories.

\section{Plausible future demographic trends}

Future living arrangements will be influenced by numerous demographic variables, but not all such variables are equally important to all outcomes. Here we focus on particular outcomes of interest-changes in population composition by household size and age of the householder (referred to as "householder age") - although we also examine results for selected additional household types. Note that the composition of the population by householder age (i.e., the percent of the population living in households headed by a householder of a particular age) is different from the population age structure, since composition by householder age reflects not only population age structure but also the age composition of households.

We select demographic variables that will be the most important determinants of these outcomes based on two sources of information: previous studies (discussed earlier) and an initial sensitivity analysis carried out with ProFamy that varies all input variables by \pm 25 percent (Jiang and O'Neill 2006; results not reported here). These considerations lead us to eliminate from consideration possible future changes in the proportion of elderly living with an adult child, the propensity of leaving the parental home, and the age at marriage or at giving birth. Changes in these variables had only a weak ef- 
fect on the household size and age composition of the US population (Jiang and $\mathrm{O}^{\prime}$ Neill 2006). ${ }^{1}$

We focus instead on fertility, mortality, migration, and rates of union formation and dissolution. The direction of the effect of most of these variables is relatively clear. A decline in fertility will lead to a reduction in household size and aging of the population as the proportion of children decreases (with opposite effects for an increase in fertility). An increase in union formation rates will lead to larger households by more frequently combining two household units into one, but will likely have minor effects on household age structure. Secondarily, household size will increase further because of the higher fertility rate of those in unions, especially marriage. Union dissolution will have the opposite effects, leading to smaller households.

The effects of changes in life expectancy and migration on aging are well known, but their effects on household size are less clear, as noted earlier. And even for variables in which the direction of an effect can be anticipated, the relative magnitudes of effects are not obvious, nor are the detailed impacts on households of particular sizes (as opposed to average household size).

Below, we discuss each of the variables in turn, presenting our high, medium, and low scenarios for subsequent use in the household projections.

\section{Fertility, life expectancy, and net migration}

Several institutions routinely develop long-term scenarios for the total fertility rate (TFR), life expectancy, and net migration, and we therefore base our own range of assumptions on this existing work. We group projections by the US Census Bureau (Hollmann et al. 2000; US Census Bureau 2004), the United Nations (UNPD 2004, 2005), the World Bank (2004), IIASA (Lutz et al. 2001), and the US Social Security Advisory Board (2003) into high, medium, and low scenarios as self-described by the institutions themselves. We then take the average of the published projections by each group to obtain our three scenarios. We use this averaging procedure since it is conservative (as compared to selecting the most extreme projections available), representative of the literature in a way that does not favor any particular institution's projection, and has some theoretical and empirical support (Sanderson 1998). Table 1 summarizes results for the year 2100 . In general, changes in TFR mainly oc-

TABLE 1 Summary of assumptions for demographic rates, United States, 2000 and 2100

\begin{tabular}{lcccc}
\hline & & $\mathbf{2 1 0 0}$ & & \\
\cline { 4 - 5 } & $\mathbf{2 0 0 0}$ & Low & Medium & High \\
\hline Total fertility rate & 2.05 & 1.5 & 2.0 & 2.5 \\
Life expectancy (years) & 76.9 & 83 & 91 & 103 \\
Net immigration (millions) & 1.05 & 0.7 & 1.3 & 2.7 \\
\hline
\end{tabular}


cur in the first 25 years, while life expectancy increases occur approximately linearly for the whole projection period. Net migration diverges across scenarios most rapidly over the first 30 years, then remains roughly constant in the medium and low scenarios while continuing to rise in the high scenario. After 2030, net migration increase/decrease occurs almost linearly for all three scenarios (for detail see Appendix Table 2 and Jiang and $\mathrm{O}^{\prime}$ Neill 2006).

\section{Union formation}

The past two decades have witnessed a surge in research on marriage and cohabitation in the United States. However, we are not aware of any reasoned projections of these trends into the future. Furthermore, quantitative studies tend to use crude rates as the measure of union formation and dissolution, which do not reflect changes in the population at risk. Because we use general rates (the ratio of demographic events to the total number of person-years at risk) in our projection, studies of trends in crude rates are not directly applicable. Here, we develop a range of scenarios we consider plausible based on historical trends and analogy to experience in European countries. Union formation consists of both marriage and cohabitation, while union dissolution consists of both divorce and cohabitation dissolution. It is difficult to consider trends in each of these rates individually, since they are closely linked to one another. We therefore first briefly review the literature and historical trends for the United States and other (primarily European) countries for all these rates, and then specify the assumptions for our scenarios.

Over the past 50-100 years US general marriage rates have been generally high compared to those of many European countries and have shared with the latter a substantial marriage boom after World War II. Following this boom, general marriage rates declined; in the Netherlands, Denmark, and Sweden these rates have stabilized or increased slightly since the 1980s, while in the United States they have continued to decline. Still, the general rate in the United States in 2000 was about 6.7 percent, whereas in these Nordic countries it was at or below 5 percent. This comparison suggests that the US rate could plausibly continue to decline. At the same time, an increase in the United States is also plausible. A study forecasting the experience of cohorts born in the 1950s and 1960s concludes that marriage in the United States will remain nearly universal for American women: close to 90 percent of women are predicted to marry (Goldstein and Kenney 2001). Moreover, forecasts that distinguish among educational groups indicate that while in the past women with more education were less likely to marry, recent college graduates will have the highest rate compared to women with lower levels of educational attainment of eventually marrying despite their later entry into marriage. This implies that general marriage rates may increase in the future when the effect of postponing marriage for education vanishes. 
The past decline in the general marriage rate has been partially offset by a rise in nonmarital cohabitation. Recent studies have improved the measurement of cohabitation and indicate a larger increase than previously thought (Baughman, Dickert-Conlin, and Houser 2002; Casper and Cohen 2000). According to an analysis of the 1987-88 National Survey of Families and Households and the 1995 National Survey of Family Growth, the general cohabitation rate among women aged 15-29 increased from 2.1 percent in the early 1970 s to 7.3 percent in the early 1990 s and 12.3 percent in 2000 , while the general marriage rate declined (Raley 2001). In 1995, the proportion of females who had entered cohabitation by age 25 reached about 45 percent. Continued increase appears plausible, since this measure has been rising with no obvious peak across a wide range of countries (UNPD 2003). Some Scandinavian and western European countries have substantially larger percentages of women entering cohabitation by age 25 as compared to the United States, for example 75 percent in Sweden, 60 percent in France, and 58 percent in Norway and Austria.

Examination of the historical relationship between general marriage rates and cohabitation rates indicates that the increase in the latter in the 1960s-1980s in the United States has been almost as great as the decline in the former-with the result that the total union formation rate has been relatively stable (Bumpass and Sweet 1989; Bumpass, Sweet, and Cherlin 1991; Manning 1993, 1995). A number of more recent studies show that cohabitation continues largely to offset the decline in marriage, with a slight decrease in the total union formation rate (Bumpass and Lu 2000; Casper and Bianchi 2002; Heuveline and Timeberlake 2004; Toulemon 1997). For example, while the proportion married by age 25 declined from 71 to 52 percent between 1977 and 1992, there was much less change over these cohorts (from 78 to 70 percent) in the proportion of women who had lived in a union. This means that more than 60 percent of the reduction in union formation due to the declining marriage rate was offset by an increasing cohabitation rate.

Whether these trends will continue to offset each other in the future is unclear. The compensating effect of cohabitation has been weakening over time. More broadly, there has been considerable debate over the relationship between cohabitation and marriage (Bianchi and Casper 2000; Brown and Booth 1996; Bumpass, Sweet, and Cherlin 1991; Clarkberg, Stolzenberg, and Waite 1995; Manning 1993, 1995; Rindfuss and VandenHeuvel 1990; Thornton 1989). Some argue that cohabitation is typically a prelude to marriage, while others maintain that cohabitation is an alternative to or substitute for marriage. In Scandinavia and some western European countries, cohabitation has become more a substitution given that an increasing number of cohabiters remain in consensual unions without marrying. In contrast, studies of the marital status transition in the United States indicate that cohabiting unmarried couples have a much higher propensity for marriage than do non- 
cohabiting unmarried persons. In a 1987-88 survey, 46 percent of cohabiters characterized their living arrangement as a precursor to marriage, while another 15 percent classified the arrangement as a trial marriage and 10 percent as a substitute for marriage. About 40 percent of all unmarried couples in this survey were married within five to seven years. More than 50 percent of couples who characterized their living arrangement as a precursor married within five to seven years, compared to 25 percent of unmarried couples in a "trial marriage" or "substitute marriage" (Casper and Sayer 2000).

\section{Union dissolution}

The general divorce rate was considerably higher in the United States than in many western European countries in the past century (Ahlburg and De Vita 1992). However, while it has continuously increased in western Europe, the divorce rate in the United States declined after 1980 and is currently not much different from the European rates. The general divorce rate in the United States dropped from 3.6 percent in 1980 to 3.1 percent in 2000, while it increased from 2.2 percent to 3.3 percent in Sweden, and from 2.0 percent to 2.8 percent in Denmark during the same period. The decrease of divorce in the United States appears to be real even considering the effect of increasing cohabitation and taking into account other compositional factors (Goldstein 1999). Therefore, it is possible that divorce will continue to decrease, with recent trends signaling a fundamental change in marriage patterns. On the other hand, given trends in Europe, particularly in Sweden where the divorce rate is higher than in the United States, it is not implausible that the US general divorce rate could increase in the future.

Our calculations indicate that the general cohabitation dissolution rate over ten years is currently 38 percent in the United States, significantly higher than the general divorce rate (Jiang and O'Neill 2006). Comparison to past trends for cohorts in low-fertility countries shows that the general cohabitation dissolution rate has become stable in eastern European countries and some other parts of Europe, such as Switzerland, the Netherlands, and Italy, at levels that are both higher and lower than the US rate.

The joint effect of divorce and cohabitation dissolution represents a substantial increase in the instability of unions in the United States (increasing from 30 percent to 38 percent dissolution over ten years) despite the decrease in the US divorce rate of the last two decades. This decreasing stability results from a decline in the proportion of cohabiters who marry their cohabiting partner (from 60 to 53 percent over this period). Similarly, unions begun by cohabitation have become less stable: the proportion of couples separating within five years of cohabiting (including those who marry after cohabiting) increased from 45 percent to 54 percent (Bumpass and Lu 2000). Data from Sweden (Bennett, Blanc, and Bloom 1988) and Canada (Balakrishnan et al. 
1987) also suggest that marriages following cohabitation are more, rather than less, likely to end in divorce.

\section{Plausible future changes in union formation}

and dissolution

The historical experience in the United States is one of more common and more stable unions-higher marriage rates and lower divorce rates-than currently exist. At the same time, European countries provide many examples of substantially less stable unions-lower marriage rates and higher cohabitation rates-than currently observed in the United States. And finally, based on international experience, a range of possible relationships exists between marriage and cohabitation, including cohabitation as either a precursor to marriage (in which case changes in marriage and cohabitation rates would move in the same direction) or a substitute for marriage (in which case marriage and cohabitation rates would be more independent, or even inversely correlated).

We incorporate in our scenarios a wide range of future possibilities by defining one set of assumptions that, taken together, lead to unions that are common and stable, and another set that leads to unions that are less common and unstable (see Table 2). Specifically, in the common and stable union case, we assume that by 2050 the general marriage rate will double (from 6.7 percent in 2000)-returning to its highest historical value, which occurred around 1950. We assume that the general cohabitation rate increases by 50 percent (rising from 12.3 percent in 2000 to 18.5 percent in 2050) or about the 2000 level in Sweden. Cohabitation in this scenario therefore serves more as a precursor to marriage than a substitute for it. We assume that the general divorce rate will decrease from 3.2 percent in 2000 to 1.5 percent in 2050 , about the level in 1950, but we do not assume a decline in the cohabitation dissolution rate. Cohabitation dissolution includes the transition to marriage, and therefore constant cohabitation dissolution seems more consistent with

TABLE 2 Summary of assumptions for union formation and dissolution rates, 2000 to 2050

\begin{tabular}{llll}
\hline & Common/stable & Medium & Less common/unstable \\
\hline Marriage & double to 1950 level & constant $^{\mathrm{b}}$ & $-55 \%$ to level of Sweden \\
Cohabitation & $+50 \%$ to level of Sweden & constant & constant \\
Divorce & $-50 \%$ to 1950 level & constant & $+25 \%$ to 1980 level \\
Cohabitation dissolution & constant & constant & $+25 \%$ to level of Sweden \\
\hline
\end{tabular}

Definition of rates: Marriage: the proportion of newly married persons to the total number of unmarried persons in the previous year; Cohabitation: the number of new cohabitants divided by the number of non-cohabiting never-married, widowed, and divorced persons in the previous year; Divorce: the number of divorces divided by the number of married couples in the previous year; Cohabitation dissolution: the number of dissolved cohabitations divided by the total number

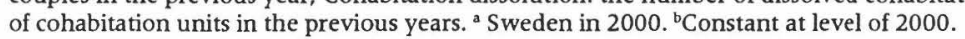


the assumptions of high rates of marriage and cohabitation. After 2050, all the union formation and dissolution rates are assumed to be constant.

For the case of less common and unstable unions, we assume that the general marriage rate will drop from 6.7 percent in 2000 to 3 percent in 2050, about the 2000 level in Sweden. In this case cohabitation acts more as a substitute for marriage; therefore to be conservative we assume that the general cohabitation rate remains constant, rather than declining along with the marriage rate. We assume that the general divorce rate increases from 3.2 percent in 2000 to 4 percent in 2050 , close to its highest level in 1980 , while the general cohabitation dissolution rate increases from 38 percent in 2000 to 48 percent, close to the 2000 Swedish level. After 2050, all the rates are assumed to be constant.

\section{Household projections for the United States}

We group our assumptions about TFR, life expectancy, migration, and union formation and dissolution into three alternative scenarios intended to span a wide range of plausible outcomes in composition by household age and household size. One end of this range is defined by a "large and young" scenario, in which we combine high TFR, modest rise in life expectancy, and high net immigration with the assumption of common and stable unions: high general union formation rates and low general union dissolution rates, as detailed in the previous section. This combination of assumptions is internally consistent given that fertility is higher within unions and among recent immigrants. This correlation among high fertility, common and stable unions, and high net immigration also implies that this combination of input assumptions is more likely than it would be if trends in each of these variables were completely independent.

The other end of the range is defined by a "small and old" scenario, in which we combine low TFR, substantial rise in life expectancy, and low net immigration with less common and unstable unions (i.e., low general union formation rates and high general union dissolution rates). In the medium scenario, all assumptions take moderate values as defined in Tables 1 and 2 (detailed values for assumptions in all three scenarios are included in Appendix Tables $2 \mathrm{a}-2 \mathrm{c}$ ).

We first conduct a household projection based on the medium scenario. Results for average household size (Figure 1) show that average size is expected to decline for 20-30 years before beginning to rise and returning to the 2000 level. This occurs despite the fact that there is little change in demographic rates: by the year 2100 TFR increases by only 1 percent, annual net immigration by 19 percent, and life expectancy by 18 percent, while union formation and dissolution rates and all other demographic variables remain 
FIGURE 1 Historical and projected population, households, and household size, United States, 1950-2000

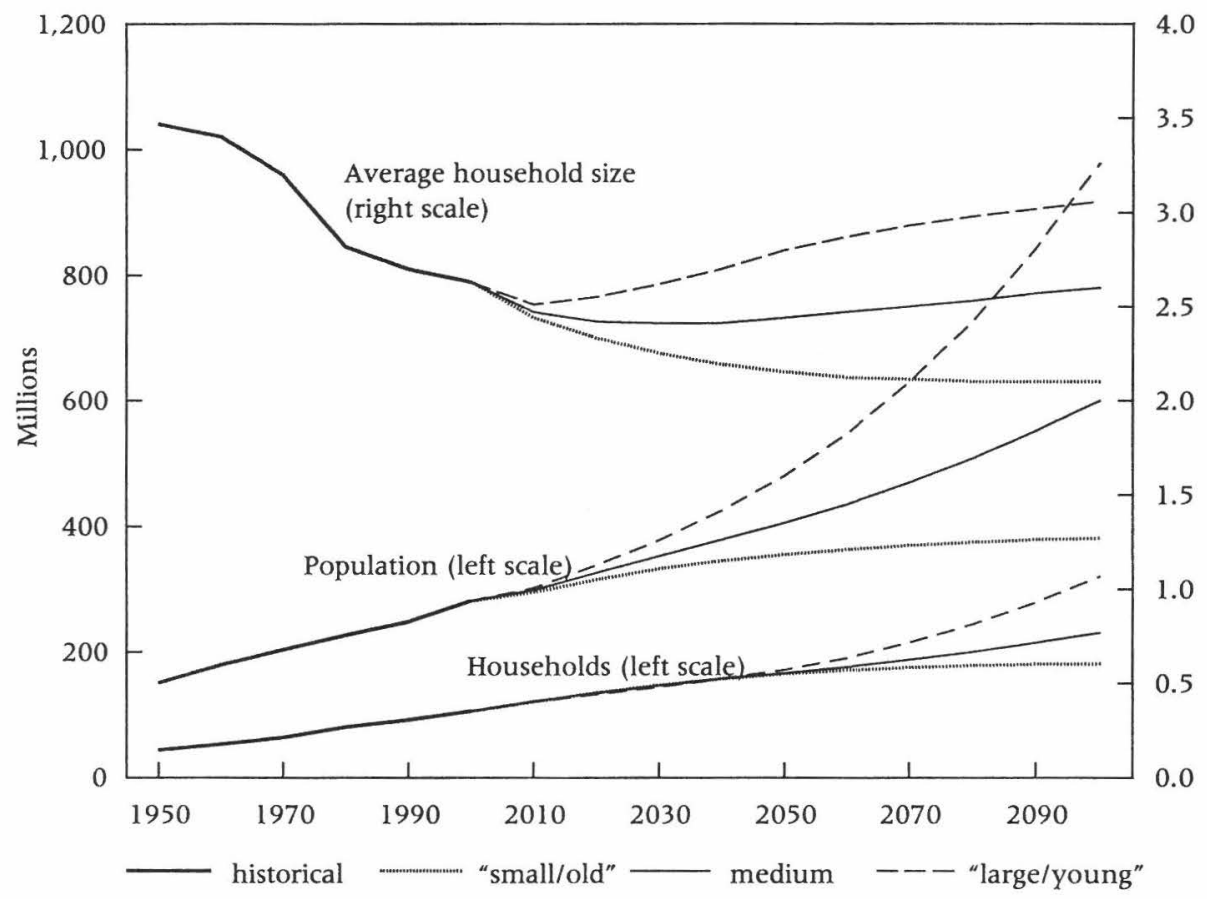

SOURCE: Historical data from US Census Bureau, Current Population Survey, March and Annual Social and Economic Supplements. 2004 and earlier "http://www.census.gov/population/socdemo/hh-fam/hh4.xls".

at the 2000 level. A projection with all inputs held constant produces much the same result.

A decomposition analysis ${ }^{2}$ shows that 60 percent of the decrease in average household size in the period $2000-2030$ is due to shifts in population age structure while 40 percent is due to changes in household headship rates that occur even in the absence of changes in demographic rates. Headship rates change as a result of the momentum of the demographic events affecting household formation and dissolution (Zeng et al. 2006). Baby boomers experienced marked changes in demographic behavior from the 1960 s to early 1980s: a low level of and postponed marriage, a rapid increase in the divorce rate, low fertility and late childbearing, and an early and high propensity of leaving the parental home. The effect of these changes on household size and structure persists as households pass through the life cycle, even after demographic rates stabilize. The number and average size of households display the longer-term and lag effects of period demographic changes. It may be particularly important to capture these changes in order to produce accurate forecasts over the next few decades. 
Next we compare results across all three scenarios. US population size and number of households continues to grow in all cases (Figure 1). Population grows from 280 million at the start of the century to 390-980 million by $2100-$ a factor of 2.6 uncertainty range. The number of households grows from 100 million to 190-310 million, a substantially smaller uncertainty range. In fact, through 2050 there is little uncertainty in the number of households. However, our results do not reflect the full range of uncertainty because the scenarios were designed to span a wide range of population size and age composition, a decision that has the effect of narrowing the range of uncertainty concerning the numbers of households.

Average household size changes from 2.6 at the beginning of the century to $2.0-3.1$ by 2100 (with most of the change occurring by 2050). In all scenarios average household size decreases over at least the first several decades, mainly owing to the changes in population age structure and household headship rates.

Our projections also provide more disaggregated results for particular household types, which are not available from a simple headship rate projection. ${ }^{3}$ Results indicate, for example, that changes in average household size

FIGURE 2 Projected proportion of population of households by household size, United States, 2000-2100

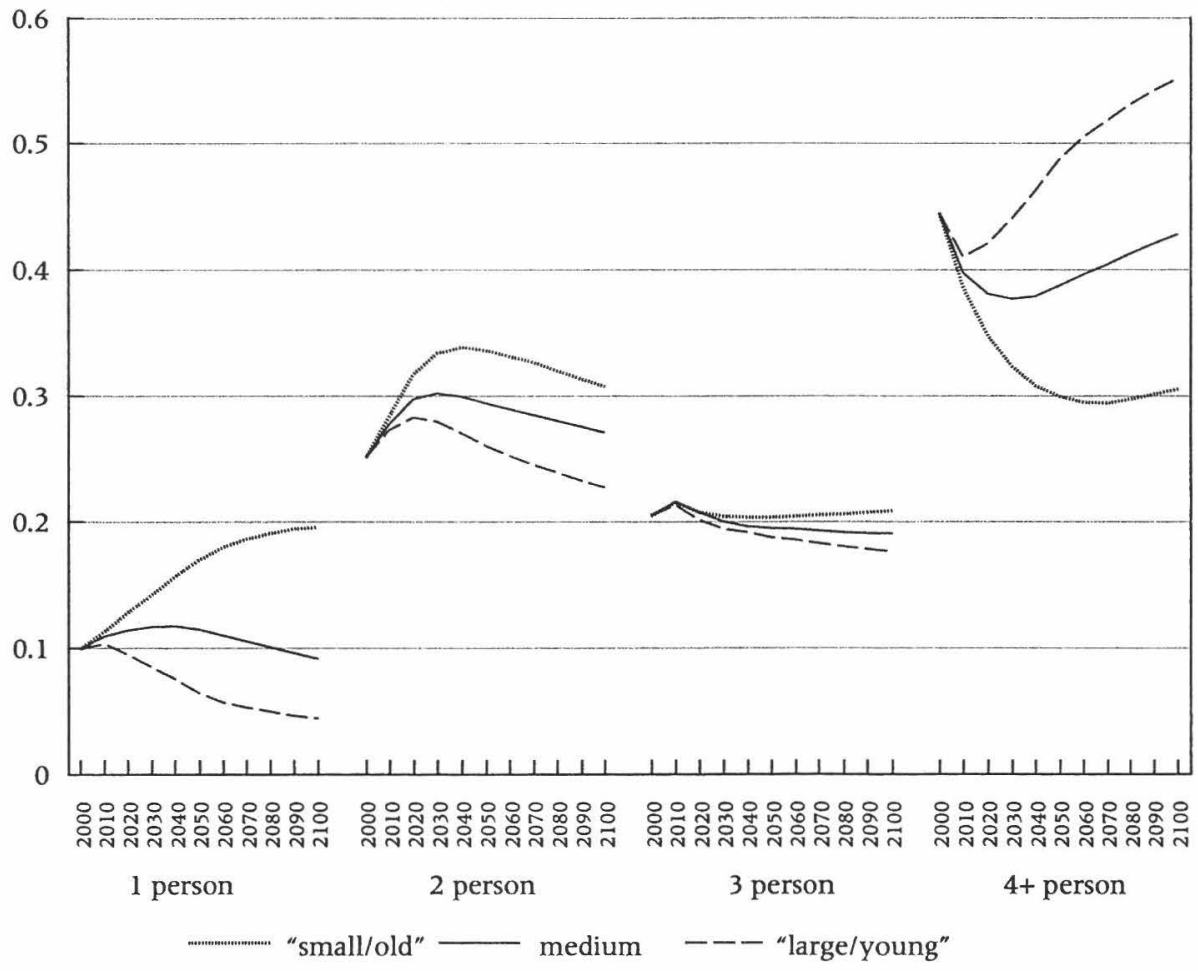


are driven primarily by a tradeoff between the proportions living in households of size $4+$ and those living in households of size 1 and 2 . There is little change in the proportion living in households of size 3 (Figure 2). Under the "small/old" scenario, the proportion of the population living in 1-person households almost doubles by 2100 , and the proportion in 2-person households increases by 40 percent by 2040 . At the same time, the proportion living in 4+-person households decreases by about 33 percent. Conversely, under the "large/young" scenario, the proportions of the population living in 1 - and 2-person households decrease by about 50 percent and 15 percent, respectively, while the share in 4+-person households increases by 33 percent.

We also analyze changes in the proportion of the population living in households headed by different age groups (Figure 3). In all scenarios there is little change in the proportion living in households headed by the middleaged (those between ages 45 and 65), while elderly households (ages 65 and older) gain, and young households (under age 45) decline, as a share of the population. This shift occurs to roughly equal degrees across scenarios over the first 30 years (due to population momentum), with the proportion living in elderly households doubling from 11 percent to 20 percent or more.

FIGURE 3 Projected proportion of the population living in households by age of the head, United States, 2000-2100

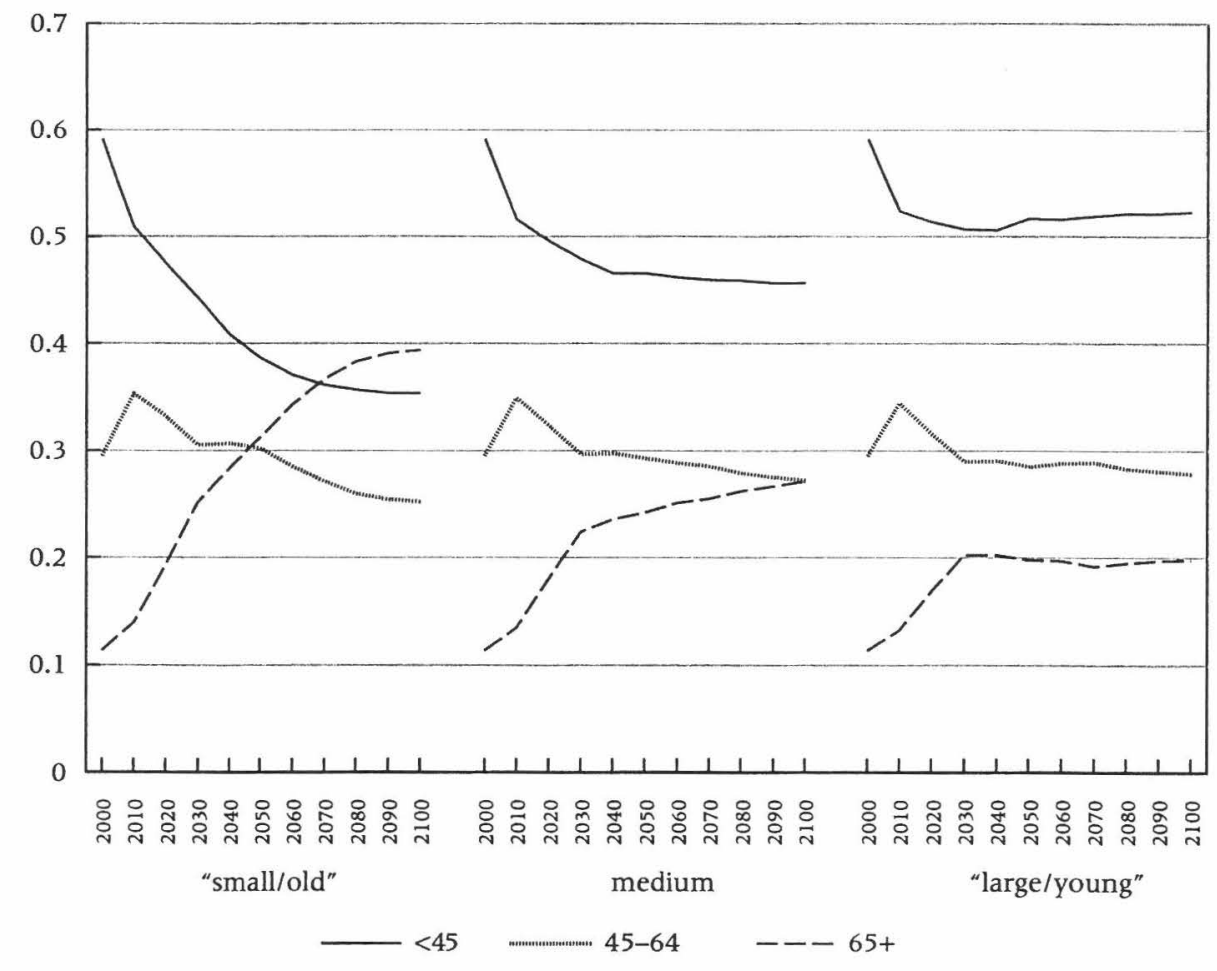


Thereafter, this proportion continues to rise to nearly 40 percent by 2100 in the "small/old" scenario, while it remains essentially constant in the "large/ young" scenario.

These results differ from those pertaining to the age structure of the population at large (projections not shown). For example, the population aged 45-64 accounts for 18-20 percent of the total population in these scenarios by 2100 , while the proportion of the population living in households headed by persons aged $45-64$ ranges from 25 to 28 percent. Results are also significantly different for the under 45 category (29-39 percent of the total population, and 35-52 percent for the population by householder age), while differences are smaller for the 65+ category (17-37 percent of the total population, and 20-39 percent for population by householder age), which is much less affected by the possible presence of children in the household.

\section{Sensitivity analysis of impacts of demographic trends on household composition}

The future changes in population composition by household type discussed in the previous section are determined by the joint effects of various demographic rates. To assess the relative importance of changes in individual demographic variables, we conduct a sensitivity analysis in which we keep all variables constant except one, testing in turn the effect of each of the variables in Tables 1 and 2 . Results show that the parameter with the strongest effect on average household size is TFR: increasing (or decreasing) TFR from about 2.0 in 2000 to 2.5 (or 1.5) in 2100 increases (or decreases) the average household size relative to the benchmark case by about 8 percent by 2100 (Figures 4 and 5). The general marriage rate is the second most influential variable. Doubling the general marriage rate by 2050 causes average household size to increase by 5 percent by 2100, while reducing it by roughly half leads to a 10 percent reduction in household size by 2100 . Changes in the general cohabitation rate also affect household size, but much more weakly than changes in the general marriage rate. The reason is that while increases in the two rates generate similar changes in the proportion of couple households, an increased marriage rate leads to a higher proportion of couple households with children, since married couples have higher fertility than cohabiting couples. In fact, a decrease in the general divorce rate induces a slightly greater impact on household size than does an increase in the cohabitation rate.

Other demographic trends-changes in net immigration, life expectancy, and the general cohabitation rate-have only a weak impact on household size. In particular, the effect of life expectancy in the high mortality scenario (the one that assumes a relatively modest increase in life expectancy by 2100 ) is not much different from that in the medium scenario. However, the direction of the (small) effect is noteworthy: an increase in life expec- 
FIGURE 4 Sensitivity analysis: Impacts of demographic events on projected average household size, United States, 2000-2100

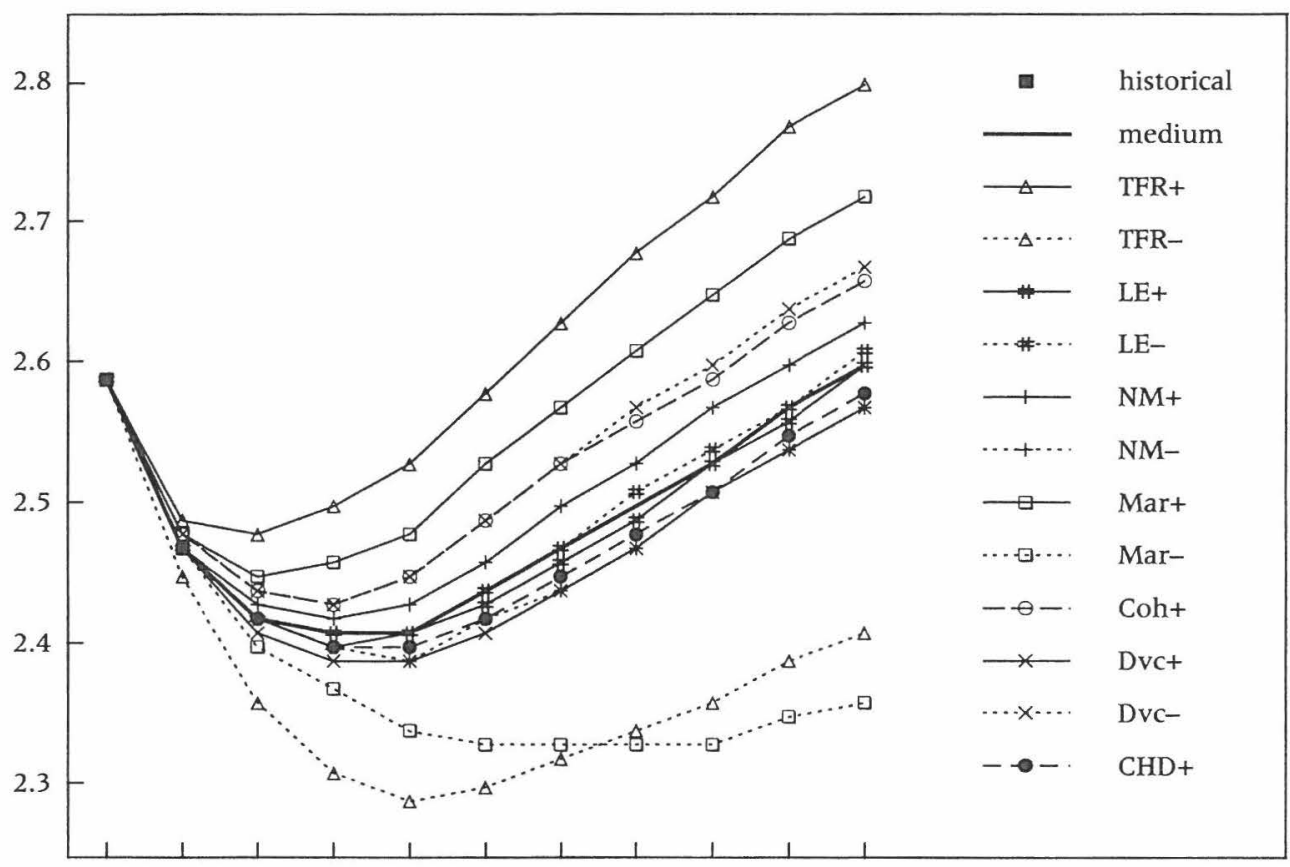

20002010202020302040205020602070208020902100

NOTE: Medium: medium scenario; TFR: Total ferrtility rate; LE: life expectancy; NM: net migration; Mar: general marriage rate; Coh: general cohabitation rate; Dvc: general divorce rate; CHD: general cohabitation dissolution rate. "+" and "-" symbols refer to high or low scenarios as defined in Tables 1 and 2.

tancy produces a smaller average household size. Increasing life expectancy increases the size of elderly households as more spouses live longer, but also increases the proportion of the population living in households headed by the elderly, a category whose household size is still small relative to the rest of the population.

Results for composition by householder age (Figure 6) are more straightforward. Variables that have a strong effect on population age structure-fertility and life expectancy-also have a substantial effect on composition by householder age. Variables such as cohabitation, divorce, and cohabitation dissolution do not substantially affect householder age structure. Changes in the general marriage rate do have some effect on composition by householder age, even though the changes do not affect population age structure. Since fertility is higher within marriage and is shifted to older ages, an increase in the marriage rate while holding TFR constant leads to a shift in population to somewhat older households. It is also noteworthy that reducing the number of net immigrants will significantly increase the proportion of elderly house- 
FIGURE 5 Sensitivity analysis: Percentage differences in average household size resulting from stipulated changes in demographic events relative to the medium scenario in 2100 , United States

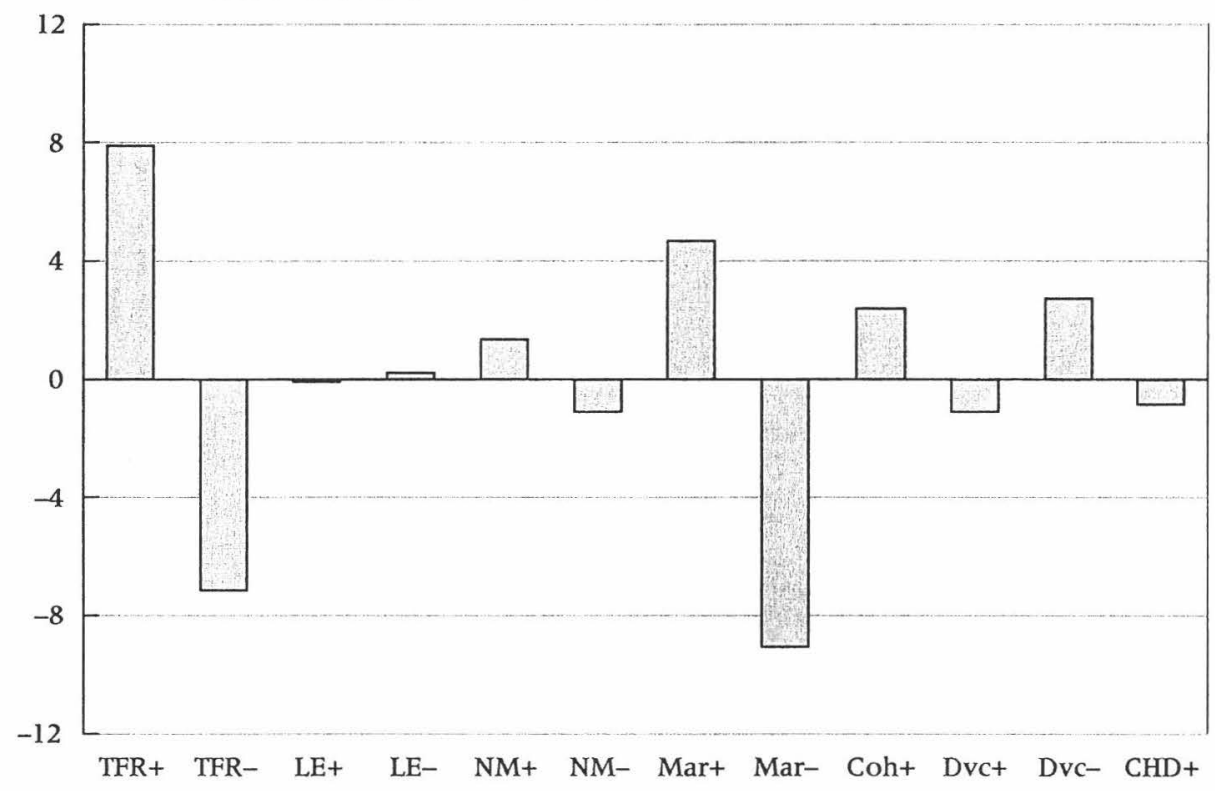

NOTE: See Note to Figure 4.

holds and decrease the proportion of young and middle-age households. In comparison, the impact of increasing the number of net immigrants is apparently smaller.

We also examine the effect of these demographic rates on household types of particular significance: one-person, couple-only, couple with children, single parent with children, and three-generation households (Appendix Table 1). In the medium scenario, one-person and couple-only households increase as a proportion of the population up to the middle of the century, then decrease to their original levels, while households consisting of couples with children change in the opposite manner: a decrease followed by a return to original levels. These effects are due to population and household momentum, as discussed above. The proportion of the population living in households containing single parents with children increases throughout the century in the medium scenario, while the proportion in three-generation households falls and remains well below original levels.

The shares of one-person and couple-only households are most sensitive to marriage and cohabitation. Increase in union formation rates leads to a sharp decrease in the population living in single-person households and an increase in couple-only households, relative to the constant scenario. Similarly, increasing the TFR leads to a substantial decrease in couple-only households 
FIGURE 6 Projected differences in the proportions of population living in the households by age of the head in 2100 relative to the constant scenario (constant $=1$ )

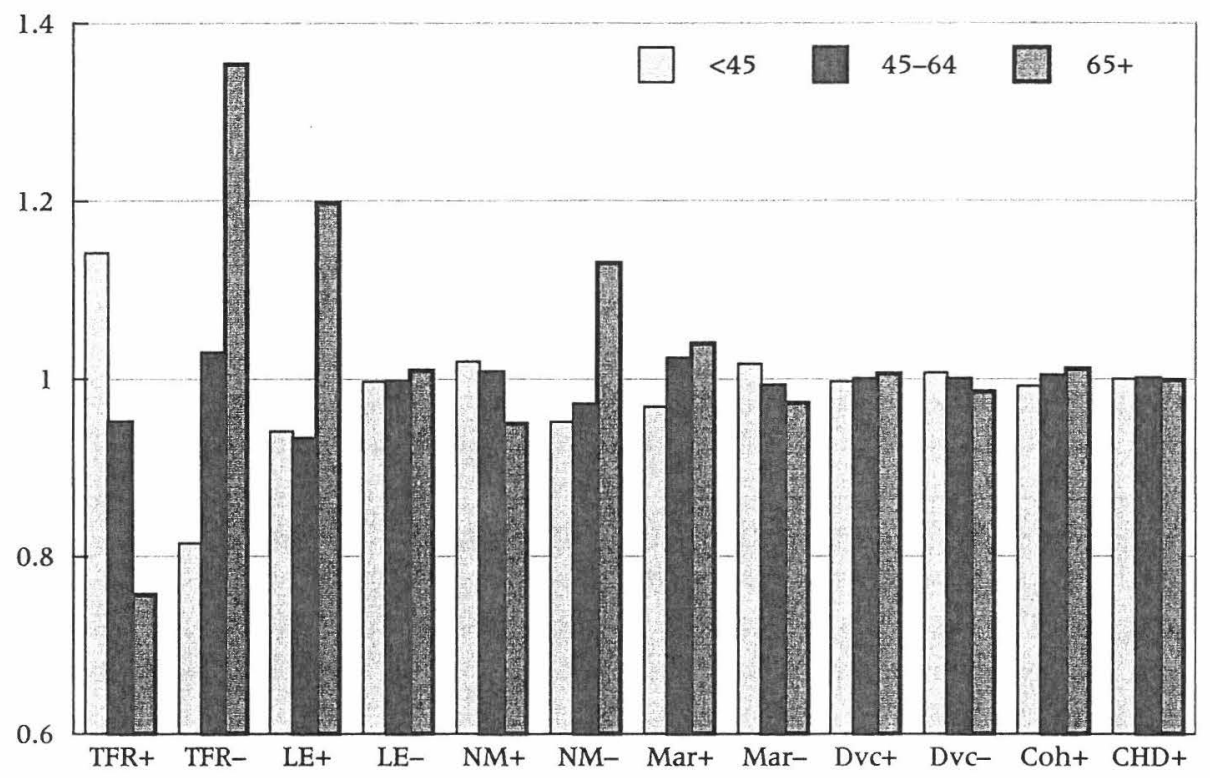

NOTE: See Note to Figure 4.

and a marked increase in households consisting of couples with children, relative to the medium scenario. Marriage rates are even more important to the changes of couple-with-children households: a declining general marriage rate induces the biggest reduction in couple-with-children households. Single-parent households (with or without children) are most affected either by fertility (increasing fertility leads to increases in the proportion living in these households) or by union formation/dissolution (more stable unions lead to a decrease in this household type). Three-generation households are also most sensitive to the changes in TFR and marriage rates.

\section{Conclusions}

We used the dynamic household projection model ProFamy to assess the sensitivity of future living arrangements in the United States to various demographic factors and to develop a range of scenarios for composition of the population by household age structure and size. These scenarios are based on new scenarios for fertility, life expectancy, and migration derived by averaging across existing scenarios in the literature, an approach that has been suggested (Sanderson 1998) but not previously been used in long-term projections. We 
also produced the first long-term scenarios for household formation and dissolution rates that are grounded in past trends, experience in other countries, and current theoretical perspectives. We anticipate that marriage rates could plausibly double, or decline by half; cohabitation rates could double; and divorce rates could increase by 25 percent or decline by half.

Our results indicate that average household size declines over the next few decades in all scenarios, mainly owing to changes in population age structure and secondarily to momentum in household formation and dissolution. By the second half of the century, the range of plausible average household size outcomes is 2.0 to 3.1, with this result being driven by tradeoffs in the proportion of the population living in one- and two-person households, on the one hand, and households of size $4+$, on the other. Our sensitivity analysis demonstrates that the most important determinants of household size composition of the population are fertility and rates of union formation and dissolution. The proportion living in households headed by the elderly $(65+)$ doubles in the "large/young" scenario, and nearly quadruples in the "small/old" scenario, to 40 percent of the population. Conversely, the proportion living in households headed by the young $(<45)$ declines substantially, from 60 percent to 35 percent.

Taken together, these results propose a range of plausible outcomes for living arrangements over the next $50-100$ years. We have been conservative in defining our scenarios, by not choosing the most extreme assumptions in the literature for the components of population change and by grounding our scenarios for union formation and dissolution rates in past experience in the United States and other countries. It is possible that unprecedented rates of demographic events could be experienced in the future, in which case this range of demographic outcomes would be expanded even further. 
APPENDIX TABLE I Sensitivity of the projected population composition by household type to demographic events (percent of total population), United States, 2000-2100

\begin{tabular}{|c|c|c|c|c|c|}
\hline & $\begin{array}{l}\text { One } \\
\text { person }\end{array}$ & $\begin{array}{l}\text { Couple } \\
\text { only }\end{array}$ & $\begin{array}{l}\text { Couple } \\
\text { with child }\end{array}$ & $\begin{array}{l}\text { Single parent } \\
\text { with child }\end{array}$ & $\begin{array}{l}\text { Three } \\
\text { generation }\end{array}$ \\
\hline \multicolumn{6}{|l|}{ Medium } \\
\hline 2000 & 25.8 & 26.8 & 31.7 & 8.5 & 3.5 \\
\hline 2030 & 28.6 & 28.8 & 26.4 & 10.2 & 1.2 \\
\hline 2050 & 28.4 & 27.3 & 27.0 & 10.9 & 1.4 \\
\hline 2100 & 24.4 & 26.9 & 30.0 & 11.6 & 1.8 \\
\hline \multicolumn{6}{|l|}{ TFR+ } \\
\hline 2030 & -0.8 & -2.5 & 2.3 & 0.9 & 0.2 \\
\hline 2050 & -1.5 & -3.9 & 3.9 & 1.5 & 0.3 \\
\hline 2100 & -2.4 & -5.2 & 5.5 & 2.3 & 0.5 \\
\hline \multicolumn{6}{|l|}{ TFR- } \\
\hline 2030 & 0.9 & 3.5 & -3.3 & -1.0 & -0.2 \\
\hline 2050 & 1.7 & 5.1 & -5.4 & -1.3 & -0.5 \\
\hline 2100 & 2.8 & 5.4 & -7.2 & -1.0 & -0.5 \\
\hline \multicolumn{6}{|l|}{ Mar+ } \\
\hline 2030 & -3.3 & 4.1 & 7.7 & -1.5 & -0.3 \\
\hline 2050 & -5.9 & 7.5 & 2.2 & -2.2 & -0.6 \\
\hline 2100 & -6.7 & 9.1 & 2.5 & -2.5 & -0.9 \\
\hline \multicolumn{6}{|l|}{ Mar- } \\
\hline 2030 & 2.1 & -2.4 & -1.4 & 1.3 & 0.2 \\
\hline 2050 & 5.0 & -5.4 & -4.3 & 3.5 & 0.3 \\
\hline 2100 & 11.1 & -10.6 & -10.4 & 7.4 & 0.4 \\
\hline \multicolumn{6}{|l|}{$\mathrm{LE}+$} \\
\hline 2030 & -0.6 & 1.3 & -0.3 & -0.3 & 0.0 \\
\hline 2050 & -0.8 & 2.1 & -0.8 & -0.4 & 0.0 \\
\hline 2100 & -1.7 & 3.8 & -0.6 & -1.1 & 0.1 \\
\hline \multicolumn{6}{|l|}{ LE- } \\
\hline 2030 & 0.0 & 0.1 & 0.0 & 0.0 & 0.0 \\
\hline 2050 & 0.0 & 0.0 & 0.0 & 0.0 & 0.0 \\
\hline 2100 & 0.0 & 0.2 & -0.1 & 0.0 & 0.0 \\
\hline \multicolumn{6}{|l|}{$\mathrm{NM}+$} \\
\hline 2030 & -0.3 & -0.5 & 0.6 & 0.3 & 0.1 \\
\hline 2050 & -0.7 & -0.9 & 1.1 & 0.4 & 0.1 \\
\hline 2100 & -0.7 & -1.1 & 1.2 & 0.5 & 0.1 \\
\hline \multicolumn{6}{|l|}{ NM- } \\
\hline 2030 & -1.1 & 2.0 & -0.4 & -0.4 & 0.1 \\
\hline 2050 & -0.6 & 1.9 & -1.0 & -0.2 & 0.0 \\
\hline 2100 & 0.0 & 1.2 & -1.0 & -0.1 & 0.1 \\
\hline \multicolumn{6}{|l|}{ Dvct } \\
\hline 2030 & 0.4 & -0.3 & -0.4 & 0.3 & 0.0 \\
\hline 2050 & 0.8 & -0.6 & -0.9 & 0.5 & 0.0 \\
\hline 2100 & 1.1 & -0.7 & -1.2 & 0.7 & 0.0 \\
\hline \multicolumn{6}{|l|}{ Dvc- } \\
\hline 2030 & -0.9 & 0.7 & 1.0 & -0.6 & 0.0 \\
\hline 2050 & -1.8 & 1.3 & 2.0 & -1.2 & 0.0 \\
\hline 2100 & -2.6 & 1.9 & 3.0 & -1.6 & 0.0 \\
\hline \multicolumn{6}{|l|}{ Coh+ } \\
\hline 2030 & -1.6 & 1.6 & 1.0 & -0.6 & 0.0 \\
\hline 2050 & -2.9 & 3.0 & 1.7 & -1.2 & -0.1 \\
\hline 2100 & -3.5 & 4.3 & 1.9 & -1.6 & -0.2 \\
\hline \multicolumn{6}{|l|}{$\mathrm{CHD}+$} \\
\hline 2030 & 0.5 & -0.5 & -0.3 & 0.2 & 0.0 \\
\hline 2050 & 1.0 & -1.0 & -0.6 & 0.4 & 0.0 \\
\hline 2100 & 1.3 & -1.4 & -0.7 & 0.6 & 0.0 \\
\hline
\end{tabular}

NOTES: See Notes to Figure 4. Households with other relatives or with nonrelatives are not included. 
APPENDIX TABLE 2a Medium scenarios for US household projection

\begin{tabular}{llllllll}
\hline & TFR & LE & NM & Mar & Coh & Dvc & CHD \\
\hline 2000 & 2.03 & 76.8 & 1110218 & 0.07 & 0.12 & 0.03 & 0.38 \\
2005 & 2.03 & 78.0 & 1079723 & 0.07 & 0.12 & 0.03 & 0.38 \\
2010 & 2.02 & 78.8 & 1015892 & 0.07 & 0.12 & 0.03 & 0.38 \\
2015 & 2.00 & 79.6 & 1041495 & 0.07 & 0.12 & 0.03 & 0.38 \\
2020 & 2.00 & 80.4 & 1065476 & 0.07 & 0.12 & 0.03 & 0.38 \\
2025 & 1.99 & 81.2 & 1161428 & 0.07 & 0.12 & 0.03 & 0.38 \\
2030 & 1.99 & 81.9 & 1249481 & 0.07 & 0.12 & 0.03 & 0.38 \\
2035 & 1.99 & 82.6 & 1248439 & 0.07 & 0.12 & 0.03 & 0.38 \\
2040 & 1.99 & 83.2 & 1251699 & 0.07 & 0.12 & 0.03 & 0.38 \\
2045 & 1.99 & 83.9 & 1257617 & 0.07 & 0.12 & 0.03 & 0.38 \\
2050 & 1.99 & 84.5 & 1265059 & 0.07 & 0.12 & 0.03 & 0.38 \\
2055 & 1.99 & 85.2 & 1268905 & 0.07 & 0.12 & 0.03 & 0.38 \\
2060 & 2.00 & 85.9 & 1273475 & 0.07 & 0.12 & 0.03 & 0.38 \\
2065 & 2.00 & 86.5 & 1278413 & 0.07 & 0.12 & 0.03 & 0.38 \\
2070 & 2.00 & 87.3 & 1283659 & 0.07 & 0.12 & 0.03 & 0.38 \\
2075 & 2.01 & 87.9 & 1289325 & 0.07 & 0.12 & 0.03 & 0.38 \\
2080 & 2.01 & 88.5 & 1295321 & 0.07 & 0.12 & 0.03 & 0.38 \\
2085 & 2.01 & 89.1 & 1301590 & 0.07 & 0.12 & 0.03 & 0.38 \\
2090 & 2.01 & 89.8 & 1308251 & 0.07 & 0.12 & 0.03 & 0.38 \\
2095 & 2.01 & 90.4 & 1315133 & 0.07 & 0.12 & 0.03 & 0.38 \\
2100 & 2.01 & 90.8 & 1322396 & 0.07 & 0.12 & 0.03 & 0.38 \\
\hline
\end{tabular}

APPENDIX TABLE $2 \mathrm{~b}$ Small household size and old age structure scenario ("small/old" scenario) for US household projection

\begin{tabular}{llllllll}
\hline & TFR & LE & NM & Mar & Coh & Dvc & CHD \\
\hline 2000 & 2.00 & 76.9 & 935069 & 0.07 & 0.12 & 0.03 & 0.38 \\
2005 & 1.83 & 78.3 & 777587 & 0.06 & 0.12 & 0.03 & 0.39 \\
2010 & 1.75 & 79.7 & 692334 & 0.06 & 0.12 & 0.03 & 0.40 \\
2015 & 1.67 & 81.2 & 681905 & 0.06 & 0.12 & 0.03 & 0.41 \\
2020 & 1.61 & 82.6 & 676296 & 0.05 & 0.12 & 0.04 & 0.42 \\
2025 & 1.59 & 84.0 & 707074 & 0.05 & 0.12 & 0.04 & 0.43 \\
2030 & 1.57 & 85.2 & 732446 & 0.04 & 0.12 & 0.04 & 0.44 \\
2035 & 1.57 & 86.4 & 717331 & 0.04 & 0.12 & 0.04 & 0.45 \\
2040 & 1.57 & 87.7 & 708322 & 0.04 & 0.12 & 0.04 & 0.46 \\
2045 & 1.57 & 89.1 & 702724 & 0.03 & 0.12 & 0.04 & 0.47 \\
2050 & 1.57 & 90.4 & 698602 & 0.03 & 0.123 & 0.04 & 0.48 \\
2055 & 1.57 & 91.8 & 695466 & 0.03 & 0.123 & 0.04 & 0.48 \\
2060 & 1.56 & 93.0 & 692651 & 0.03 & 0.123 & 0.04 & 0.48 \\
2065 & 1.56 & 94.6 & 689804 & 0.03 & 0.123 & 0.04 & 0.48 \\
2070 & 1.56 & 95.7 & 686816 & 0.03 & 0.123 & 0.04 & 0.48 \\
2075 & 1.56 & 97.4 & 683906 & 0.03 & 0.123 & 0.04 & 0.48 \\
2080 & 1.56 & 98.6 & 681180 & 0.03 & 0.123 & 0.04 & 0.48 \\
2085 & 1.56 & 100.1 & 678498 & 0.03 & 0.123 & 0.04 & 0.48 \\
2090 & 1.55 & 101.5 & 676080 & 0.03 & 0.123 & 0.04 & 0.48 \\
2095 & 1.55 & 102.5 & 673772 & 0.03 & 0.123 & 0.04 & 0.48 \\
2100 & 1.55 & 103.5 & 671704 & 0.03 & 0.123 & 0.04 & 0.48 \\
\hline
\end{tabular}


APPENDIX TABLE 2C Large household size and young age structure scenario ("large/young" scenario) for US household projection

\begin{tabular}{llllllll}
\hline & TFR & LE & NM & Mar & Coh & Dvc & CHD \\
\hline 2000 & 2.02 & 76.47 & 1316348 & 0.07 & 0.12 & 0.03 & 0.38 \\
2005 & 2.20 & 76.99 & 1494753 & 0.07 & 0.13 & 0.03 & 0.38 \\
2010 & 2.28 & 77.54 & 1491751 & 0.08 & 0.14 & 0.03 & 0.38 \\
2015 & 2.32 & 78.05 & 1601934 & 0.09 & 0.14 & 0.03 & 0.38 \\
2020 & 2.35 & 78.64 & 1697708 & 0.10 & 0.15 & 0.03 & 0.38 \\
2025 & 2.36 & 79.17 & 1936451 & 0.10 & 0.15 & 0.02 & 0.38 \\
2030 & 2.37 & 79.56 & 2169402 & 0.11 & 0.16 & 0.02 & 0.38 \\
2035 & 2.38 & 79.81 & 2214463 & 0.12 & 0.17 & 0.02 & 0.38 \\
2040 & 2.37 & 80.16 & 2258698 & 0.13 & 0.17 & 0.02 & 0.38 \\
2045 & 2.38 & 80.36 & 2301723 & 0.13 & 0.18 & 0.02 & 0.38 \\
2050 & 2.39 & 80.78 & 2343678 & 0.14 & 0.18 & 0.02 & 0.38 \\
2055 & 2.40 & 80.98 & 2386430 & 0.14 & 0.18 & 0.02 & 0.38 \\
2060 & 2.41 & 81.27 & 2428252 & 0.14 & 0.18 & 0.02 & 0.38 \\
2065 & 2.42 & 81.52 & 2469008 & 0.14 & 0.18 & 0.02 & 0.38 \\
2070 & 2.42 & 82.01 & 2508931 & 0.14 & 0.18 & 0.02 & 0.38 \\
2075 & 2.43 & 82.15 & 2548442 & 0.14 & 0.18 & 0.02 & 0.38 \\
2080 & 2.44 & 82.27 & 2587483 & 0.14 & 0.18 & 0.02 & 0.38 \\
2085 & 2.44 & 82.42 & 2626136 & 0.14 & 0.18 & 0.02 & 0.38 \\
2090 & 2.44 & 82.67 & 2664467 & 0.14 & 0.18 & 0.02 & 0.38 \\
2095 & 2.44 & 82.68 & 2702588 & 0.14 & 0.18 & 0.02 & 0.38 \\
2100 & 2.44 & 82.72 & 2740520 & 0.14 & 0.18 & 0.02 & 0.38 \\
\hline
\end{tabular}

\section{Notes}

1 The independent effect of increasing age at marriage is always to drive down average household size, since postponement of marriage means more people living in small non-family households for longer. However, the impact of changes in mean age at childbearing is more complicated. Our preliminary analysis using the ProFamy model indicates that increasing mean age at childbearing causes fluctuations in average household size (Jiang and $O^{\prime}$ Neill 2006). The shift in the period fertility schedule caused by delayed childbearing increases the fertility of women in older childbearing years, while decreasing the fertility of women in younger childbearing years. The net period effect on births depends on the age structure. In the United States, the age structure during the period 2000-2030 favors increased births and therefore has a positive effect on household size. Later, age structure favors fewer births and exerts a negative effect on average size.

2 The analysis is available on request: Leiwen_Jiang@Brown.edu

3 We compared ProFamy results to those from a projection in which age-specific headship rates are held constant at their current values and combined with the ProFamy projection of population age structure. Differences in the projected total number of households are generally only a few percent, except in the "large/young" scenario, in which they reach 10 percent by the end of the century (differences in average household size are slightly smaller). The benefit of using an approach more sophisticated than constant headship rates is therefore in the possibility of obtaining numbers of households by type rather than simply the total number of households. 


\section{References}

Ahlburg, D. and C. De Vita. 1992. "New realities of the American family," Population Bulletin 47: $1-50$.

Balakrishnan, T. R., K. Vaninadha Rao, E. Lapierre-Damcyk, and K. J. Krotki. 1987. “A hazard model analysis of the covariates of marriage dissolution in Canada," Demography 24(3): 395-406.

Baughman, Reagan, Stacy Dickert-Conlin, and Scott Houser. 2002. "How well can we track cohabitation using the SIPP? A consideration of direct and inferred measures," Demography 39: 455-465.

Bennett, N. G., A. K. Blank, and D. E. Bloom. 1998. "Commitment and the modern union: Assessing the link between premarital cohabitation and subsequent marital stability," American Sociological Review 53(1): 127-138.

Bianchi, S. M., and L. Casper. 2000. "American families," Population Bulletin 55(4).

Bongaarts, John. 1987. "The projection of family composition over the life course with family status life tables," in J. Bongaarts, T. Burch, and K. W. Wachter (eds.), Family Demography: Methods and Applications. Oxford: Clarendon Press.

Brown, S. L. and A. Booth. 1996. “Cohabitation versus marriage: A comparison of relationship quality," Journal of Marriage and the Family 58: 668-678.

Bumpass, Larry and Hsien-Hen Lu. 2000. "Trends in cohabitation and implications for children's family contexts in the United States," Population Studies 54: 29-41.

Bumpass, Larry and J. Sweet. 1989. "National estimates of cohabitation," Demography 26: $615-625$.

Bumpass, Larry, J. A. Sweet, and A. Cherlin. 1991. "The role of cohabitation in declining rates of marriage," Journal of Marriage and the Family 53: 913-927.

Burch, Thomas K. 1970. "Some demographic determinants of average household size: An analytic approach," Demography 7: 61-69.

Burch, Thomas K. and Beverly J. Matthews. 1987. "Household formation in developed societies," Population and Development Review 13: 495-511.

Burr, Jeffrey A. and Jan E. Mutchler. 1993. "Ethnic living arrangements: Cultural covergency or cultural minifestation," Social Forces 72: 169-179.

Carliner, Geoffrey. 1975. "Determinants of household headship," Journal of Marriage and the Family 37: 28-38.

Carlsson-Kanyama, A. and A. L. Linden. 1999. "Travel patterns and environmental effects now and in the future: Implications of differences in energy consumption among socioeconomic groups," Ecological Economics 30: 405-417.

Casper, Lynne and S. M. Bianchi. 2002. Continuity and Change in the American Family. Thousand Oaks, CA: Sage.

Casper, Lynne and P. N. Cohen. 2000. "How does POSSLQ measure up? Historical estimates of cohabitation," Demography 37: 237-245.

Casper, Lynne and L. C. Sayer. 2000. "Cohabitation transitions: different attitudes and purposes, different paths," paper presented at the Annual Meeting of the Population Association of America, Los Angeles, 23-25 March.

Clarkberg, M. E., R. M. Stolzenberg, and L. J. Waite. 1995. "Attitudes, values, and entrance into cohabitation versus marital union," Social Forces 77: 945-968.

Dalaker, J. 1999. "Poverty in the United States: 1998," Table 2. US Census Bureau, Current Population Reports, P60-207. Washington, DC: US Government Printing Office.

Dalton, M., B. C. O'Neill, A. Prskawetz, L. Jiang, and J. Pitkin. 2006. "Population aging and future carbon emissions in the United States," Energy Economics, "doi:10.1016/ j.eneco.2006.07.002".

Deaton, A. and C. Paxson. 2000. "Growth and saving among individuals and households," Review of Economics and Statistics 82 (2): 212-225.

Ermisch, J. F. and Elizabeth Overton. 1985. "Minimal household units: A new approach to the analysis of household formation," Population Studies 39: 33-54. 
Gokhale, Jagadeesh, Laurence J. Kotlikoff, and John Sabelhaus. 1996. "Understanding the post-war decline in U.S. saving: A cohort analysis," BPEA 1: 315-407.

Goldstein, Joshua R. 1999. "The leveling of divorce in the United States," Demography 36: $409-414$.

Goldstein, Joshua R. and Catherine T. Kenney. 2001. "Marriage delayed or marriage forgone? New cohort forecasts of first marriage for US women," American Sociological Review 66: 506-519.

Heuveline, Patrick and Jeffrey M. Timeberlake. 2004. "The role of cohabitation in family formation: The United States in comparative perspective," Journal of Marriage and the Family 66: 1-21.

Hollman, F. W., T. J. Mulder, and J. E. Kallan. 2000. "Methodology and assumptions for the population projections of the United States: 1999 to 2100," Population Division Working Paper, US Census Bureau.

Holmberg, I. 1987. "Household change and housing needs: A forecasting model," in J. Bongaarts, T. Burch, and K. Watchter (eds.), Family Demography: Methods and Their Application. Oxford: Clarendon Press.

Hullen, G. 2003. Living Arrangements and Households: Methods and Results of Demographic Projections. Bundesinstitut für Bevolkerngsforschung.

Hunton, Laura. 1998. "Growth in Mexican-immigrant and Mexican-American households: The implication for planning," Working paper, School of Public and Environmental Affairs, Indiana University.

Jiang, Leiwen. 1999. Population and Sustainable Development in China: Scenarios for Two Regions. Amsterdam: Thela Thesis.

Jiang, Leiwen and Brian C. O'Neill. 2006. "Impacts of demographic events on US household change," Interim Report IR-06-030, IIASA, Laxenburg, Austria.

King, D. 1999. "Official household projections in England: Methodology, usage and sensitivity tests," paper presented at Joint ECE-EUROSTAT work session on Demographic Projections, Perugia, Italy, 3-7 May.

Kobrin, Frances E. 1973. "Household headship and its changes in the United States, 1940-1960, 1970," Journal of the American Statistical Association 68: 793-800.

1976. "The fall in household size and the rise of the primary individual in the United States," Demography 13: 127-138.

Liu, J., C. C. Dally, P. R. Ehrlich, and G. W. Luck. 2003. "Effects of household dynamics on resource consumption and biodiversity," Nature 421: 530-533.

Lutz, W. et al. 2001. "The end of world population growth," Nature 412(6846): 490-491.

MacCracken, M. S. D., E. S. Brondizio, D. Nelson, E. F. Moran, A. D. Siqueira, and C. Rodriguez-Pedraza. 1999. "Remote sensing and GIS at farm property level: Demography and deforestation in the Brazilian Amazon," Photogrammetric Engineering and Remote Sensing 65: $1311-1320$.

MacKellar, F. L., W. Lutz, C. Prinz, and A. Goujon. 1995. "Population, households, and $\mathrm{CO}_{2}$ emissions," Population and Development Review 21(4): 849-865.

Manning, W. D. 1993. "Marriage and cohabitation following premarital conception," Journal of Marriage and the Family 55: 839-850.

-1995. "Cohabitation, marriage, and entry into motherhood," Journal of Marriage and the Family 55: 839-850.

Martin, N. 1999. "Population, households and domestic water use in countries of the Mediterranean Middle East," Laxenburg, Austria: IIASA, IR-99-032.

Muller, C., Kottai S. Gnanasekaran, and Kenneth Knapp. 1999. Housing and Living Arrangements of the Elderly: An International Comparison Study. New York: International Longevity Center-USA, Ltd. Almanac Phase 4.

O'Neill, B. C. and B. S. Chen. 2002. "Demographic determinants of household energy use in the United States," in W. Lutz, A. Prskawetz, and W. Sanderson (eds.), Population and Environment: Methods of Analysis, Supplement to Population and Development Review 28: 53-88. 
O'Neill, B., F. L. MacKellar, and W. Lutz. 2001. Population and Climate Change. Cambridge: Cambridge University Press, UK.

Perz, S. G. 2001. "Household demographic factors as life cycle determinants of land use in the Amazon," Population Research and Policy Review 20: 159-186.

Prskawetz, Alexia, Leiwen Jiang, and Brian C. O'Neill. 2004. "Demographic composition and projections of car use in Austria," Vienna Yearbook of Population Research, 2004: 247-326.

Raley, R. K. 2001. "Increasing fertility in cohabiting unions: Evidence for the second demographic transition in the United States?," Demography 38: 59-66.

Richards, Toni, Michael J. White, and Amy Ong Tsui. 1987. "Changing living arrangements: A hazard model of transitions among household types," Demography 24: 77-97.

Rindfuss, Ronald and Audrey VandenHeuvel. 1990. "Cohabitation: A precursor to marriage or an alternative to being single?," Population and Development Review 16: 703-726.

Sanderson, W. C. 1998. "Knowledge can improve forecasts: A review of selected socioeconomic population projection models," in W. Lutz, J. Vaupel, and D. Ahlburg (eds.), Frontiers of Population Forecasting, Supplement to Population and Development Review 24: 88-1 17.

Santi, Lawrence L. 1987. "Change in the structure and size of American households: 1970 to 1985," Journal of Marriage and the Family 49: 833-837. - 1988. "The demographic context of recent change in the structure of American households," Demography 25: 509-519.

Select Committee on Environment. 1998. Transport and Regional Affairs. 1998: Tenth Report. The United Kingdom Parliament.

Social Security Advisory Board. 2003. 2003 Technical Panel on Assumptions and Methods. Washington, DC.

Sweet, James A. 1984. "Components of change in the number of households: 1970-1980," Demography 21: 129-140.

Teachman, Jay D. 1982. "Methodological issues in the analysis of family formation and dissolution," Journal of Marriage and the Family 44: 1037-1053.

Thornton, A. 1989. "Changing attitudes toward family issues in the United States," Journal of Marriage and the Family 51: 873-893.

Toulemon, L. 1997. "Cohabitation is here to stay," Population: An English Selection 9: 11-56.

Tsai, I. J., C. Y. C. Chu, and C. F. Chung. 2000. "Demographic transition and household saving in Taiwan," Population and Development Review 26(Supp.): 174-193.

UNPD. 2003. Partnership and Reproductive Behavior in Low-Fertility Countries. New York.

- 2004. "World population to 2300," ST/ESA/SER.A/236, New York. 2005. World Population Prospects: The 2004 Revision. New York.

US Census Bureau. 2004. "Interim projections of the US population by age, sex, race, and Hispanic origin: Summary, methodology, and assumptions." Washington, DC: United States Government Printing Office.

. 2005. "Current Population Survey, March and Annual Social and Economic Supplement," 2004 and earlier, Washington DC.

Van Diepen., A. 1995. "Population, land use and housing trends in the Netherlands since 1950," Laxenburg, International Institute for Applied Systems Analysis (IIASA), wp-95-63.

Watkins, Susan Cotts, Jane A. Menken, and John Bongaarts. 1987. "Demographic foundation of family change," American Sociological Review 52: 346-358.

White, Michael J. and Amy Ong Tsui. 1986. "A panel study of family-level structural change," Journal of Marriage and the Family 48: 435-446.

Wilkes, Robert E. 1995. "Household life-cycle stages, transitions, and product expenditures," The Journal of Consumer Research 22(1): 27-42.

World Bank. 2004. "World development indicators 2004," CD-ROM. Washington, DC.

Zeng, Yi. 1986. "Changes in family structure in China: a simulation study," Population and Development Review 12: 675-703.

. 1988. "Changing demographic characteristics and the family status of Chinese women," Population Studies 42: 183-203. 
1991. Family Dynamics in China: A Life Table Analysis. Wisconsin: University of Wisconsin Press.

Zeng, Yi, Kenneth C. Land, Zhenglian Wang, and Danan Gu. 2006. "U.S. family household momentum and dynamics: An extension and application of the ProFamy method," Population Research and Policy Review 15: 1-41.

Zeng, Yi, James Vaupel, and Zhenglian Wang. 1997. “A multidimensional model for projecting family households, with an illustrative numerical application," Mathematical Population Studies 6: 187-216.

. 1998. "Household projection using conventional demographic data." Population and Development Review 24(Supp.): 59-87.

Zeng, Yi, Zhenglian Wang, Leiwen Jiang, and Danan Gu. Forthcoming. "Projection of family households and elderly living arrangement in the context of rapid population aging in China-A demographic window of opportunity until 2030 and serious challenges thereafter, GENUS. 
. 